\title{
Controllable synthesis and catalytic performance of graphene-supported metal oxide nanoparticles
}

\author{
Yingsi $\mathrm{Wu}, \mathrm{Hao} \mathrm{Yu}^{*}$, Hongjuan Wang, Feng Peng \# \\ School of Chemistry and Chemical Engineering, South China University of Technology, Guangzhou 510640, Guangdong, China
}

\section{A R T I C L E I N F O}

Article history:

Received 18 March 2014

Accepted 18 April 2014

Published 20 June 2014

\section{Keywords:}

Particle size

Graphene

Metal oxide

Hydrogen peroxide

Benzyl alcohol

\begin{abstract}
A B S T R A C T
The size of nanoparticles plays a crucial role in their performance. In this article, three methods, i.e., direct impregnation, homogeneous oxidative precipitation with hydrogen peroxide, and ammonia-catalyzed hydrolysis, were applied to synthesize iron, cobalt, and nickel metal oxide nanoparticles supported on graphene. The influence of the three deposition methods on particle size distribution was investigated. Transmission electron microscopy, Fourier transform infrared spectroscopy, $\mathrm{X}$-ray diffraction, and X-ray photoelectron spectroscopy were used to characterize the morphology and structure of the catalysts. The highest dispersion and the most uniform particle size distribution were obtained by the hydrogen peroxide homogeneous oxidative precipitation method. Hydrogen peroxide favors the maximization of the oxygen-containing groups on graphenes, thereby providing sufficient absorption and nucleation sites to give a high dispersion of nanoparticles. In contrast, ammonia accelerates the nucleation speed and results in the largest particle size and inhomogeneity. The catalytic properties of the graphene-supported metal oxide nanoparticles were tested with the oxidation of benzyl alcohol as a probe reaction. The reaction activity decreased in the following order: catalysts prepared by hydrogen peroxide-assisted deposition $>$ direct impregnation $>$ ammonia-catalyzed hydrolysis. The decrease in reaction activity was consistent with the order of increasing catalyst particle sizing shown in transmission electron microscopy images. The catalytic relevance of the particle size showed a necessity for the development of effective methods for size-controlled nanocatalyst synthesis on graphenes.
\end{abstract}

(C) 2014, Dalian Institute of Chemical Physics, Chinese Academy of Sciences.

Published by Elsevier B.V. All rights reserved.

\section{Introduction}

The size of nanoparticles (NPs) plays a crucial role in their performance. Smaller particle sizes offer higher surface-tovolume ratios, and thus, larger amounts of high energy sites on surfaces. For example, controlling the size of particles used in energy applications can lead to significantly enhanced surface-to-volume ratios and short transport lengths for the mobile charges [1]. Nano-sized NiO showed a higher capacity and energy efficiency in lithium-ion batteries when compared with sub-micro-sized NiO [2]. The reduced particle size was responsible for the reduction in the charge-discharge hysteresis loop, and thus, higher reversible capacity and more stable cycle performance. Exceptional behaviors may also emerge at specific size ranges or in particular particle shapes [3]. For instance, it is well known that $\mathrm{Au}$ is highly active for low-temperature $\mathrm{CO}$ oxidation when the size of the Au particles is in the range 2-5 $\mathrm{nm}[4,5]$.

\footnotetext{
* Corresponding author. Tel/Fax: +86-20-87114916; E-mail: yuhao@scut.edu.cn

\# Corresponding author. Tel/Fax: +86-20-87114916; E-mail: cefpeng@scut.edu.cn

This work was supported by the National Natural Science Foundation of China (20806027, 21273079), the Natural Science Foundation of Guangdong Province (S20120011275), and the Program for New Century Excellent Talents in University (NCET-12-0190). DOI: 10.1016/S1872-2067(14)60114-5 | http://www.sciencedirect.com/science/journal/18722067 | Chin. J. Catal., Vol. 35, No. 6, June 2014
} 
Iron family metals ( $\mathrm{Fe}, \mathrm{Co}, \mathrm{Ni}$ ) are attracting more and more interest for their low prices and excellent performance in catalysis, such as hydrogenation [6], CO oxidation [7], alcohol oxidation [8], and electrochemistry [9]. The preparation of size-controllable $\mathrm{Fe}, \mathrm{Co}$, and $\mathrm{Ni}$ metal/metal oxide NPs can contribute much to the design of highly active non-noble catalysts. For Fe catalysts used in Fischer-Tropsch (FT) synthesis, the specific activity may increase 6 to 8 -fold while the average iron carbide size decreases from 7 to $2 \mathrm{~nm}$ [10]. However, for Co catalysts, the specific activity of FT processes does not depend on the Co particle size when in the range 9-200 nm. For particles smaller than $7 \mathrm{~nm}$, larger Co particles result in increased turnover frequency and $\mathrm{C}_{5}{ }^{+}$selectivity [11]. Yang et al. [12] reported that Co NPs dispersed in the mesoporous carbon exhibited a higher selectivity with decreasing particle size in the CO hydrogenation reaction. Pina et al. [13] reported that the hydrodechlorination of aromatic compounds over $\mathrm{Ni} / \mathrm{SiO}_{2}$ catalysts was dependent on the $\mathrm{Ni}$ particle size. Larger particles favor the specific $\mathrm{Cl}$ removal, owing to the intrinsic electronic properties and metal/support interactions.

Graphene is widely used as an excellent support for highly dispersed metal nanocatalysts owing to its excellent electronic, thermal, and mechanical properties and high surface area [14-17]. Graphene oxide (G0), a derivative of graphene, possesses abundant oxygen-containing groups and defects, making it suitable for anchoring NPs. The resulting nanocomposites are promising in catalysis [18], energy conversion and storage $[19,20]$, electronics and sensors [21,22]. A number of methods have been used to synthesize graphene-metal nanoparticle composites. The simplest approach is the direct growth from metal precursors on the surface of GO by electrostatic interaction at elevated temperatures [23]. The oxygenated functional groups anchor the metal ions for nucleation and GO is reduced during the depletion of the functional groups. In many cases, reducing agents, such as $\mathrm{NaBH}_{4}$ [24], L-ascorbic acid [25], and hydrazine hydrate [26] were needed to reduce the ions to metal particles. $\mathrm{NH}_{3} \cdot \mathrm{H}_{2} \mathrm{O}$ is commonly employed to aid the hydrolysis of metal ions $[27,28]$, followed by reduction or decomposition of the metal hydroxide in a certain atmosphere to obtain metal/oxide-graphene composites. So far, efforts have been made to control the sizes of Fe, Co, and Ni NPs supported on graphenes by varying the starting precursor concentration [29], reaction time [30], annealing temperature [31], and the thickness of the additive agents [32]. However, the composites obtained by the above methods differ not only in the particle size, but also the metal loading, materials composition, and the reduction degree of GO.

When GO is used as a support, the abundant oxygen-containing groups on its surface provides sufficient absorbing and nucleation sites for metal ions. Thus, the dispersion of the supported NPs can be controlled by adjusting the amount of the functional groups. Our previous studies showed that metal oxide NPs can be dispersed on carbon nanotubes (CNTs) by a $\mathrm{H}_{2} \mathrm{O}_{2}$ homogeneous oxidative precipitation (HOP) method $[33,34]$, in which ultrafine oxide particles can be easily loaded on CNTs under mild conditions, without using any surfactants or corrosive reagents and without any emissions from the pro- cess except water. Herein, we present Fe, Co, and Ni metal oxide NPs grown on reduced GO (RGO) with the $\mathrm{H}_{2} \mathrm{O}_{2}$ HOP method. By comparing with direct impregnation and ammonia-catalyzed hydrolysis, the influence of the deposition method on the particle size distribution was investigated and their catalytic performances were tested in the oxidation of benzyl alcohol.

As one of the most important reactions for the synthesis of valuable chemical intermediates, the aerobic oxidation of benzyl alcohol in the liquid phase has attracted much research interest. The most commonly used catalysts for this reaction are precious metals, such as $\mathrm{Au}, \mathrm{Pt}, \mathrm{Ru}$, and $\mathrm{Pd}$ [35-37]. Some base transition metal ( $\mathrm{Fe}, \mathrm{Co}, \mathrm{Ni}$ ) catalysts were prepared to replace the noble metals [8,38-40]. The size and shape dependency of catalysts for reaction performance has been discussed [8], indicating that fine particle sizes $(<5 \mathrm{~nm})$ is favored by the liquid phase benzyl alcohol oxidation. However, the preparation of size-controllable non-precious catalysts and the impact of size have not been investigated clearly and need further research. Therefore, in this paper, the influence of preparation conditions on the metal NP size and the size effect on the alcohol oxidation performance will be studied.

\section{Experimental}

\subsection{Preparation of $\mathrm{MeO}_{x} / \mathrm{RGO}(\mathrm{Me}=\mathrm{Fe}, \mathrm{Co}, \mathrm{Ni})$ nanocomposites}

Graphite oxide was prepared by a modified Hummers method with natural flake graphite as the carbon source (325 mesh, Alfa Aesar) [41]. First, $3 \mathrm{~g}$ of graphite was added to a solution of concentrated $\mathrm{H}_{2} \mathrm{SO}_{4}(30 \mathrm{~mL}), \mathrm{K}_{2} \mathrm{~S}_{2} \mathrm{O}_{8}(10 \mathrm{~g})$, and $\mathrm{P}_{2} \mathrm{O}_{5}$ (10 g) and heated at $80{ }^{\circ} \mathrm{C}$ for $4.5 \mathrm{~h}$. After cooling to room temperature, the mixture was diluted with deionized (DI) water, filtered and dried. The pre-oxidized graphite was added to $120 \mathrm{~mL}$ of concentrated $\mathrm{H}_{2} \mathrm{SO}_{4}$. Fifteen grams of $\mathrm{KMnO}_{4}$ was added slowly whilst keeping the mixture below $20{ }^{\circ} \mathrm{C}$. The mixture was then stirred at $35^{\circ} \mathrm{C}$ for $2 \mathrm{~h}$, diluted with $250 \mathrm{~mL}$ of DI water and stirred for an additional $2 \mathrm{~h}$. After adding 700 mL of DI water, $30 \% \mathrm{H}_{2} \mathrm{O}_{2}$ solution $(20 \mathrm{~mL})$ was injected dropwise. The color of the solution turned to a bright yellow. The product was collected by filtration and washed by $1 \mathrm{~L}$ of $\mathrm{H}_{2} \mathrm{O} / \mathrm{HCl}$ solution $(10: 1, v / v)$. The product was then re-dispersed in DI water at $8 \mathrm{~g} / \mathrm{L}$ and dialyzed for 1 week until the dialysate $\mathrm{pH}$ was neutral, to obtain graphite oxide. GO was prepared by exfoliating graphite oxide in DI water using sonication for $2 \mathrm{~h}$. The concentration of the suspension was 1 $\mathrm{mg} / \mathrm{mL}$.

To prepare $\mathrm{FeO}_{x} / \mathrm{RGO}, 15 \mathrm{~mL}$ of $12 \mathrm{mmol} / \mathrm{L} \mathrm{FeSO}_{4}$ aqueous solution was added into the $\mathrm{GO} / \mathrm{H}_{2} \mathrm{O}$ suspension dropwise while stirring. After ultrasonication for $2 \mathrm{~h}$, the suspension was stirred at room temperature overnight for ion exchange. Subsequently, $1.6 \mathrm{~mL}$ of $\mathrm{H}_{2} \mathrm{O}_{2}$ aqueous solution (30 wt\%) was added to the suspension dropwise, followed by stirring at $80{ }^{\circ} \mathrm{C}$ for $4 \mathrm{~h}$ to obtain the $\mathrm{Fe}(\mathrm{OH})_{x} / \mathrm{GO}$ precursor. The solids, denoted here as $\mathrm{Fe}(\mathrm{OH})_{x} / \mathrm{GO}-\mathrm{HP}$, were collected by centrifugation and lyophilization. For comparison, the impregnated sample, denoted as $\mathrm{Fe}(\mathrm{OH})_{x} / \mathrm{GO}-\mathrm{I}$, was prepared without adding $\mathrm{H}_{2} \mathrm{O}_{2}$. We 
also used $0.1 \mathrm{~mL} \mathrm{NH} \mathrm{N}_{3} \cdot \mathrm{H}_{2} \mathrm{O}$ solution (25 wt\%) to assist the hydrolysis of $\mathrm{Fe}^{2+}$ and form the metal hydroxide precursor on GO. The resulting composites were denoted as $\mathrm{Fe}(\mathrm{OH})_{x} / \mathrm{GO}-\mathrm{N}$. Similarly, $\mathrm{Co}(\mathrm{OH})_{x} / \mathrm{GO}-\mathrm{HP}, \mathrm{N}$, I and $\mathrm{Ni}(\mathrm{OH})_{x} / \mathrm{GO}-\mathrm{HP}, \mathrm{N}$, I were prepared by substituting $\mathrm{Co}(\mathrm{OAc})_{2} \cdot 4 \mathrm{H}_{2} \mathrm{O}$ or $\mathrm{Ni}(\mathrm{OAc})_{2} \cdot 4 \mathrm{H}_{2} \mathrm{O}$ for $\mathrm{FeSO}_{4} \cdot 7 \mathrm{H}_{2} \mathrm{O}$ with the same concentration. The hydroxide precursors were heated rapidly $\left(\sim 80^{\circ} \mathrm{C} / \mathrm{min}\right)$ to $500{ }^{\circ} \mathrm{C}$ in $\mathrm{Ar}$ and reduced in $10 \% \mathrm{H}_{2} / \mathrm{Ar}$ at that temperature for $2 \mathrm{~h}$. After cooling to room temperature and exposing to air, the resulting composites, denoted as $\mathrm{MeO}_{x} / \mathrm{RGO}(\mathrm{Me}=\mathrm{Fe}, \mathrm{Co}$, Ni), were obtained. Table 1 lists the nomenclature, metal oxide loadings, and textural properties of the catalysts used in this work.

\subsection{Sample characterizations}

Low- and high-resolution transmission electron microscopic (HRTEM) images were taken on FEI Tecnai G2 12 and JEOL JEM-2010 transmission electron microscopes operated at 100 and $200 \mathrm{kV}$, respectively. Fourier transform infrared (FTIR) spectra were recorded in the $4000-400 \mathrm{~cm}^{-1}$ region on a $\mathrm{Ni}-$ colet 6700 spectrometer by pelletizing with $\mathrm{KBr}$. X-ray photoelectron spectroscopy (XPS) was performed on an Axis Ultra DLD (Kratos) spectrometer equipped with an $\mathrm{Al} K_{\alpha}$ X-ray source. All spectra were calibrated by setting the $\mathrm{C} 1 \mathrm{~s}$ signal to the binding energy of $284.6 \mathrm{eV}$, fitting with Gaussian peaks and subtracting a Shirley type background. $\mathrm{N}_{2}$ adsorption measurements were conducted on a Micromeritics ASAP 2010 apparatus. X-ray diffraction (XRD) data were obtained by a D8 Advance X-ray diffractometer (German Bruker) with $\mathrm{Cu} K_{\alpha}$ radiation $(40 \mathrm{kV}, 40 \mathrm{~mA})$ at a scan rate of $0.02^{\circ} / 17.7 \mathrm{~s}$. The loading of metal oxides was determined by thermogravimetric analysis (TGA) under air from room temperature to $900{ }^{\circ} \mathrm{C}$.

\subsection{Catalytic tests}

Catalysts $\left(10 \mathrm{mg}\right.$ ) were mixed with $5 \mathrm{~mL}$ of $\mathrm{CH}_{3} \mathrm{CN}$ to form homogeneous suspensions by sonication, and then $100 \mathrm{mg}$ benzyl alcohol and $0.4 \mathrm{~mL} t$-butyl hydroperoxide (TBHP, 70\%) were added. Mixtures were heated in a flask to $80{ }^{\circ} \mathrm{C}$ and stirred at $500 \mathrm{r} / \mathrm{min}$ under ambient pressure for 1-6 h. The conversion was analyzed on a FuLi 9790 gas chromatograph.
Table 1

Nomenclature, metal oxide loadings and textural properties of $\mathrm{CoO}_{x} / \mathrm{RGO} \mathrm{FeO}_{x} / \mathrm{RGO}$, and $\mathrm{NiO}_{x} / \mathrm{RGO}$ catalysts.

\begin{tabular}{lrrc}
\hline Catalyst & $\mathrm{MeO}_{x}(\%)$ & $S_{\text {BET }}\left(\mathrm{m}^{2} / \mathrm{g}\right)$ & Pore volume $\left(\mathrm{cm}^{3} / \mathrm{g}\right)$ \\
\hline $\mathrm{CoO}_{x} /$ RGO-HP & 8.6 & 153.7 & 0.70 \\
$\mathrm{CoO}_{x} /$ RGO-N & 9.0 & 177.2 & 1.25 \\
$\mathrm{CoO}_{x} /$ RGO-I & 13.2 & 225.0 & 1.18 \\
$\mathrm{FeO}_{x} /$ RGO-HP & 16.3 & 103.7 & 0.82 \\
$\mathrm{FeO}_{x} /$ RGO-N & 15.6 & 209.4 & 0.84 \\
$\mathrm{FeO}_{x} /$ RGO-I & 16.8 & 150.7 & 0.68 \\
$\mathrm{NiO}_{x} /$ RGO-HP & 11.7 & 243.2 & 1.22 \\
$\mathrm{NiO}_{x} /$ RGO-N & 14.5 & 133.3 & 0.41 \\
$\mathrm{NiO}_{x} /$ RGO-I & 10.7 & 301.1 & 1.49 \\
\hline
\end{tabular}

\section{Results and discussion}

The numbers of defects and oxygen-containing functional groups on the surfaces of GO determine the adsorption and nucleation of metal ions. To controllably form nano-sized particles on graphenes, it is desirable to harness the amount and evolution of the defects and functional groups during the synthesis. Three approaches were conducted to prepare Me$\mathrm{O}_{x} / \mathrm{RGO}$ nanocomposites, i.e., the direct impregnation, $\mathrm{H}_{2} \mathrm{O}_{2}$ HOP and the hydrolysis with $\mathrm{NH}_{3} \cdot \mathrm{H}_{2} \mathrm{O}$. Figure 1 illustrates the two-step growth of metal oxide on GO by the three methods. The direct impregnation resulted in the spontaneous oxidation and hydrolysis of precursors on GO while GO was reduced owing to the oxygen exchange between functional groups and adsorbed metal ions [42]. However, the depletion of oxygencontaining groups may result in inhomogeneity in the nucleation of particles. The final size distribution was determined by the Ostwald ripening in solution and the subsequent $\mathrm{H}_{2}$ reduction step. As a result, some large particles were formed owing to the agglomeration of small nuclei to reduce the system energy. To improve the homogeneity of the formation of nanoparticles, the oxygen-containing groups should be kept abundant on GO surfaces. Based on this idea, hydrogen peroxide was used to increase the number of oxygen-containing groups during adsorption and nucleation. Hydrogen peroxide has been widely reported as an oxidant to modify carbon materials [43]. By continuously oxidizing the GO surface, new sites for adsorp-

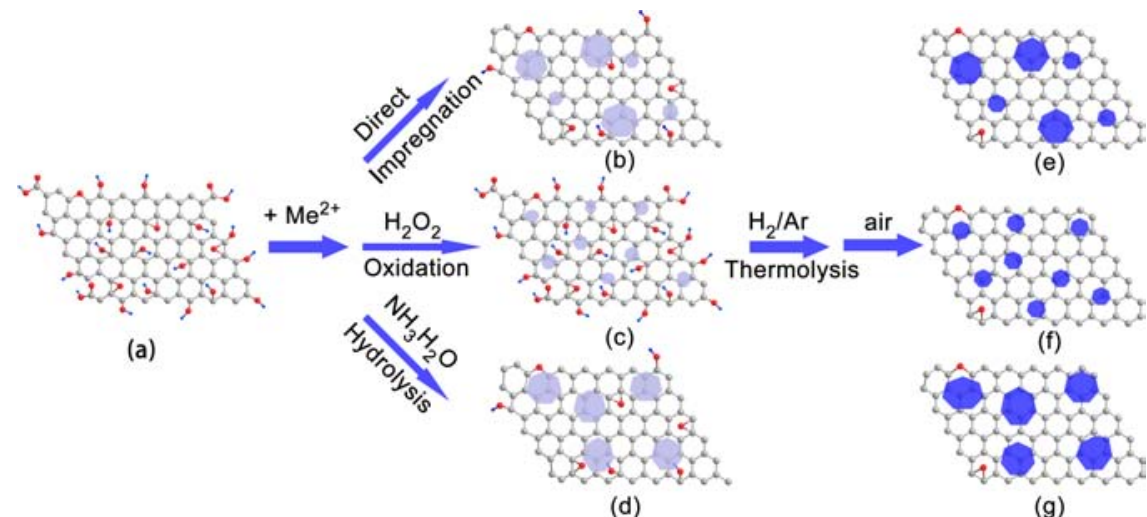

Fig. 1. Schematic diagram of size-controllable metal oxide NPs grown on RGO. (a) GO; (b-d) Me(OH) $x /$ GO-I, HP, N; (e-g) MeO $x /$ RGO-I, HP, N. Gray balls: $\mathrm{C}$ atoms; red balls: $\mathrm{O}$ atoms; blue balls: $\mathrm{H}$ atoms. Light blue sheets: metal hydroxide precursors; blue particles: metal oxides. The disproportionate size of the NPs and the carbon hexagonal rings is designed for better readability. 
tion and nucleation were created and thus improved the dispersion. Besides achieving a homogeneous distribution of sites to anchor particles, the formation of nanoparticles can also be tuned by altering the nucleation process. Assisted by ammonia, the precursors hydrolyzed rapidly to form numerous tiny crystallite nuclei in solution, which were subsequently adsorbed and grew on the GO surface.

Figure 2 shows the TEM images and size distributions of Fe, Co, and Ni NPs on RGO obtained by the three methods. The wrinkled and transparent sheet structure indicates the presence of thin graphene layers. It was found that the heating conditions during the thermolysis step have great influence on the structure of graphene. When the composites were rapidly heated, the products expanded in the porcelain boat, owing to the gases $\left(\mathrm{CO}_{2}, \mathrm{CO}\right)$ released by the decomposition of oxygen-containing groups. The conventional heating (ramping rate of $10{ }^{\circ} \mathrm{C} / \mathrm{min}$ ) resulted in restacking and agglomeration among graphene sheets, leading to quite a low surface area $\left(<1 \mathrm{~m}^{2} / \mathrm{g}\right)$. The TEM images of $\mathrm{FeO}_{x}$ NPs prepared with direct impregna- tion, $\mathrm{H}_{2} \mathrm{O}_{2} \mathrm{HOP}$ and $\mathrm{NH}_{3} \cdot \mathrm{H}_{2} \mathrm{O}$ hydrolysis are presented in Fig. 2(a)-(c). The impregnation with $\mathrm{FeSO}_{4}$ generated NPs on RGO with a mean size of $7.0 \mathrm{~nm}$, while aggregates of NPs were occasionally observed. The introduction of oxidative $\mathrm{H}_{2} \mathrm{O}_{2}$ effectively improved the homogeneity of NPs. Fine and uniform NPs with an average size of $3.6 \mathrm{~nm}$ and a standard deviation $(\sigma)$ of $17 \%$ were formed by the $\mathrm{H}_{2} \mathrm{O}_{2}$ HOP method. Speeding up the hydrolysis with ammonia significantly increased the particle size and inhomogeneity. When $\mathrm{NH}_{3} \cdot \mathrm{H}_{2} \mathrm{O}$ was used, the mean diameter of NPs increased to $7.8 \mathrm{~nm}$ with a wider distribution ( $\sigma=19 \%$ ). Similar trends were found in $\mathrm{CoO}_{x}$ (Fig. 2(d)-(f)) and $\mathrm{NiO}_{x}$ (Fig. 2(g)-(i)) catalysts. These results were consistent with the previous prediction that the highest NP dispersion could be achieved by the $\mathrm{H}_{2} \mathrm{O}_{2}$ HOP method, emphasizing the crucial role of oxygen-containing groups of RGO. Meanwhile, the comparative study among the three methods established a library for synthesizing RGO supported NPs with different sizes for diverse applications involving reactions with size effects.

Interestingly, particles with larger diameters exhibited ob-
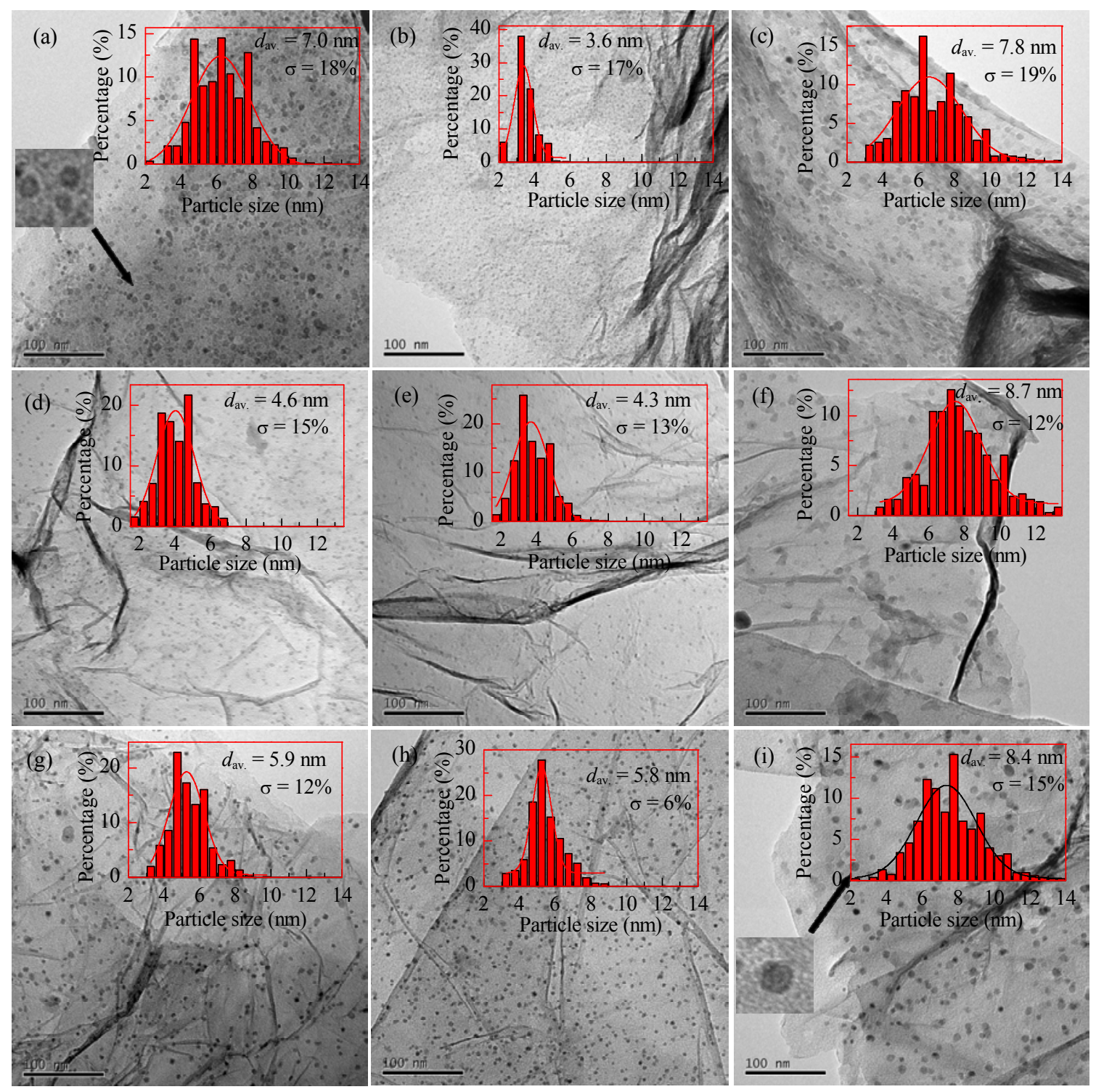

Fig. 2. TEM images of $\mathrm{FeO}_{x} /$ RGO-I, HP, $\mathrm{N}\left(\mathrm{a}-\mathrm{c}\right.$ ), $\mathrm{CoO}_{x} /$ RGO-I, HP, N (d-f), $\mathrm{NiO}_{x} / \mathrm{RGO}-\mathrm{I}, \mathrm{HP}, \mathrm{N}$ (g-i). 
vious hollow and core-void-shell morphology, as shown in the insets of Fig. 2(a) and (i). They were formed during the process from reduction by air exposure. When metal NPs are exposed to air, small metallic NPs may be completely oxidized to metal oxides $[34,44]$. For larger particles, the nanoscale Kirkendall effect, originating from the mismatched outward diffusion rates of metal cations, led to voids or core-void-shell structures in the particles. The hollow structures offer larger amounts of active sites on the nanoparticles [45].

FTIR (Fig. 3) was applied to investigate the variation of oxygen-containing groups on GO during the precursor deposition and thermal reduction. Figure 3(a) shows the abundant functionalities on GO $[46,47]$. The broad and intense absorption band at $3413 \mathrm{~cm}^{-1}$ is from the $\mathrm{O}-\mathrm{H}$ stretching vibration of absorbed water molecules. The characteristic band at $1732 \mathrm{~cm}^{-1}$ can be assigned to $\mathrm{C}=\mathrm{O}$ stretching vibration from $\mathrm{O}=\mathrm{C}-\mathrm{H}$ groups. The peak at $1624 \mathrm{~cm}^{-1}$ is attributed to aromatic $\mathrm{C}=\mathrm{C}$ stretching. The bands at 1396, 1226, and $1061 \mathrm{~cm}^{-1}$ correspond to the $\mathrm{O}-\mathrm{H}$ stretching vibrations of $\mathrm{C}-\mathrm{OH}, \mathrm{C}-\mathrm{O}$ of epoxy, and $\mathrm{C}-\mathrm{O}$ of alkoxy groups, respectively. After $\mathrm{Co}(\mathrm{OH})_{x}$ was deposited on GO, most of the IR bands were retained, but the peak intensities of $\mathrm{C}=\mathrm{O}\left(1732 \mathrm{~cm}^{-1}\right), \mathrm{C}-\mathrm{OH}\left(1396 \mathrm{~cm}^{-1}\right)$, and epoxy $\left(1226 \mathrm{~cm}^{-1}\right)$ groups decreased, indicating that the metal precursor occupied their positions to form nuclei. As a result, the $\mathrm{C}=0$ peak at $1732 \mathrm{~cm}^{-1}$ of $\mathrm{Co}(\mathrm{OH})_{x} / \mathrm{RGO}-\mathrm{N}$, I (Fig. 3(c),(d)) almost disappeared. However, a stronger $\mathrm{C}=0$ peak was observed in $\mathrm{Co}(\mathrm{OH})_{x} / \mathrm{RGO}-\mathrm{HP}$, demonstrating the effect of $\mathrm{H}_{2} \mathrm{O}_{2}$ on in-situ forming oxygen-containing groups as aforementioned. After treating in $\mathrm{H}_{2} / \mathrm{Ar}$ (Fig. 3(e)-(g)), the absorbance bands at 1732, 1396 , and $1226 \mathrm{~cm}^{-1}$, which were related to functional groups on GO, had completely vanished and indicated a thorough thermal reduction of GO to RGO. Owing to the 2-D structure of graphenes and the anchoring effect of oxygen-containing groups [48], the NPs on graphenes can be stabilized to fulfill the requirements of catalytic tests. Taking $\mathrm{CoO}_{x} / \mathrm{RGO}-\mathrm{I}$ as an example, a strong $200 \mathrm{~W}$ ultrasonic bath for up to $1 \mathrm{~h}$ resulted in a leaching of only $5.7 \mathrm{wt} \%$ Co from the catalyst, suggesting the stability of NPs on graphenes.

The composition of the Co catalyst was analyzed by XRD

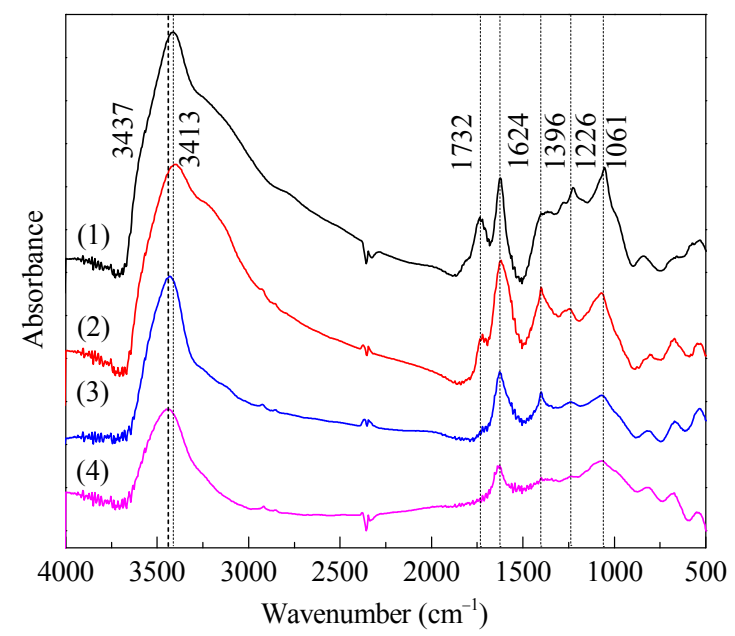

(Fig. 4(a)). In the $\mathrm{CoO}_{x} /$ RGO-HP composite, no characteristic peaks ascribed to the cobalt phase were detected, suggesting that cobalt oxides formed on RGO were amorphous or very small owing to the line boardening of nano-crystallites [18]. HRTEM was applied to investigate the structure of the nanoparticles (Fig. 4(b)). Lattice fringes with $0.236 \mathrm{~nm}$ intervals corresponded to the (311) facets of $\mathrm{Co}_{3} \mathrm{O}_{4}$ or (111) facets of CoO. XPS was used to further determine the oxidation state of cobalt in the composite (Fig. 4(c)). Co was detected on the surfaces of $\mathrm{CoO}_{x} / \mathrm{RGO}-\mathrm{HP}$ at $4.2 \mathrm{wt} \%$, which was slightly less than the content determined by TG analysis ( $6.3 \mathrm{wt} \%$ ), indicating a high dispersion of the cobalt species. Figure 4(d) shows the high-resolution peaks of Co $2 p_{3 / 2}$ and Co $2 p_{1 / 2}$ at 780.3 and $796.3 \mathrm{eV}$, respectively. The existence of $\mathrm{Co}^{0}$ can be excluded where $\mathrm{Co}^{0}$ typically shows a binding energy at $\sim 778.2 \mathrm{eV}$ [49]. The deconvoluted peak of $\mathrm{Co}^{3+}$ at $779.6 \mathrm{eV}$ and that of $\mathrm{Co}^{2+}$ at $780.6 \mathrm{eV}$ indicated the presence of $\mathrm{Co}_{3} \mathrm{O}_{4}$. Meanwhile, the shake-up satellite at $786.3 \mathrm{eV}$ is in accordance with $\mathrm{CoO}$ [49]. Thus, the sample is proposed to be a mixture of $40 \% \mathrm{Co}_{3} \mathrm{O}_{4}$ and $60 \%$ CoO. To rule out the effect of the Co oxidation state on performance, the high-resolution Co $2 p$ spectra of $\mathrm{CoO}_{x} / \mathrm{RGO}-\mathrm{N}$ and $\mathrm{CoO}_{x} /$ RGO-I were examined (Fig. 4(e) and (f)). It can be seen that $\mathrm{CoO}_{x} / \mathrm{RGO}-\mathrm{N}$ and $\mathrm{CoO}_{x} / \mathrm{RGO}-\mathrm{I}$ were composed of $\mathrm{CoO}$ and $\mathrm{Co}_{3} \mathrm{O}_{4}$, with $56 \%$ and $57 \% \mathrm{CoO}$ in the cobalt oxide mixture, respectively, being very close to that of $\mathrm{CoO}_{x} / \mathrm{RGO}-\mathrm{HP}$. These results indicated that the $\mathrm{CoO}_{x} / \mathrm{RGO}$ catalysts all had similar composition.

The oxidation of benzyl alcohol was employed as a probe reaction to investigate the performance of the catalysts. $\mathrm{CoO}_{x} / \mathrm{RGO}$ exhibited nearly complete conversion of benzyl alcohol within $6 \mathrm{~h} . \mathrm{FeO}_{x} / \mathrm{RGO}$ and $\mathrm{NiO}_{x} /$ RGO showed moderate and quite low conversions, respectively. The results are in agreement with the previous reports. Co and Fe oxides were reported as the promising catalysts for aerobic oxidation of benzyl alcohol. $\mathrm{NiO}$ showed poor activity, while $\mathrm{Ni}(\mathrm{OH})_{2}$ was more efficient than $\mathrm{NiO}$, owing to the formation of $\mathrm{Ni}$-alkoxide on the $\mathrm{Ni}(\mathrm{OH})_{2}$ catalyst [50]. Owing to the high activity of Co catalysts, the effect of the synthesis method on the activity was investigated for Co catalysts. All $\mathrm{CoO}_{x}$ samples exhibited con-

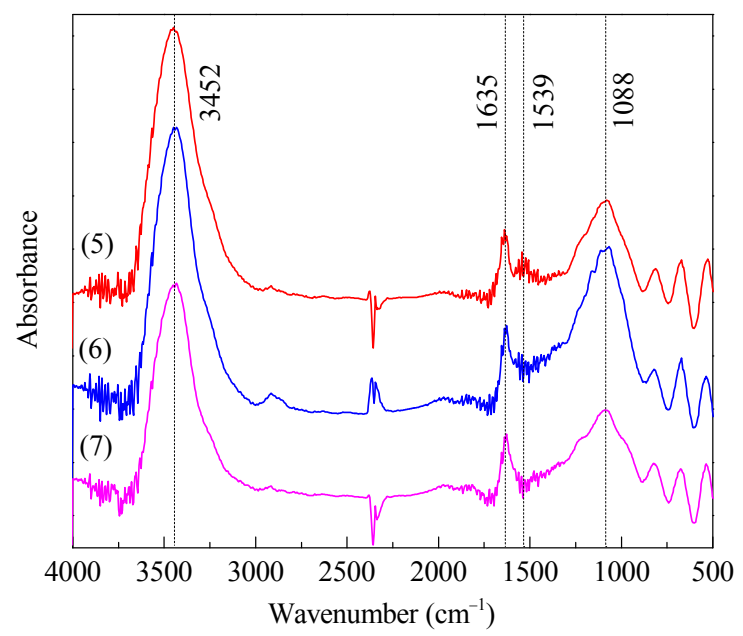

Fig. 3. FTIR spectra of GO (1), $\mathrm{Co}(\mathrm{OH})_{x} / \mathrm{GO}-\mathrm{HP}, \mathrm{N}, \mathrm{I}(2-4)$, and $\mathrm{CoO}_{x} / \mathrm{RGO}-\mathrm{HP}, \mathrm{N}, \mathrm{I}(5-7)$. 
siderable conversion (Fig. 5(b)). The activity decreased in the order $\mathrm{CoO}_{x} / \mathrm{RGO}-\mathrm{HP}>\mathrm{CoO}_{x} / \mathrm{RGO}-\mathrm{I}>\mathrm{CoO}_{x} / \mathrm{RGO}-\mathrm{N}$ and is consistent with the increasing order of Co catalyst particle sizes revealed in Fig. 2. Currently, the precise turnover frequency of the Co catalysts cannot be extracted owing to the lack of information on the amount and structure of the catalytic sites on the oxide surface. However, a comparison can be made by using the reciprocal diameter of catalyst particles as a relative measure of active sites. As shown in Fig. 5(b), a good correlation between the pseudo-first-order rate constant and $1 / d$ demonstrated that the activity of $\mathrm{CoO}_{x}$ catalysts was dependent on the exposed catalytic surface. The highest activity, corresponding to $\mathrm{CoO}_{x} / \mathrm{RGO}-\mathrm{HP}$, can be ascribed to the small and uniform par- ticle size. In this work, we took the oxidation of benzyl alcohol as a model reaction, where no structural sensitivity was considered. However, it is clear that the particle sizes of $\mathrm{CoO}_{x}, \mathrm{FeO}_{x}$, and $\mathrm{NiO}_{x}$ can be controlled by using different synthesis methods and that the catalytic activity can be tuned. This phenomenon is important to processes with unique size effects, such as FT synthesis, where extraordinary selectivity and activity were observed for iron and cobalt catalysts. Smaller particle sizes of iron carbide lead to higher methane selectivities in the FT synthesis of lower olefins [10]. However, larger cobalt NPs in the range of 4-15 $\mathrm{nm}$ were found to favor the dissociation of $\mathrm{CO}$ in FT reactions [51]. It is thus expected that the size-controlled Co, $\mathrm{Fe}$, and Ni NP catalysts may be good candidates for numerous
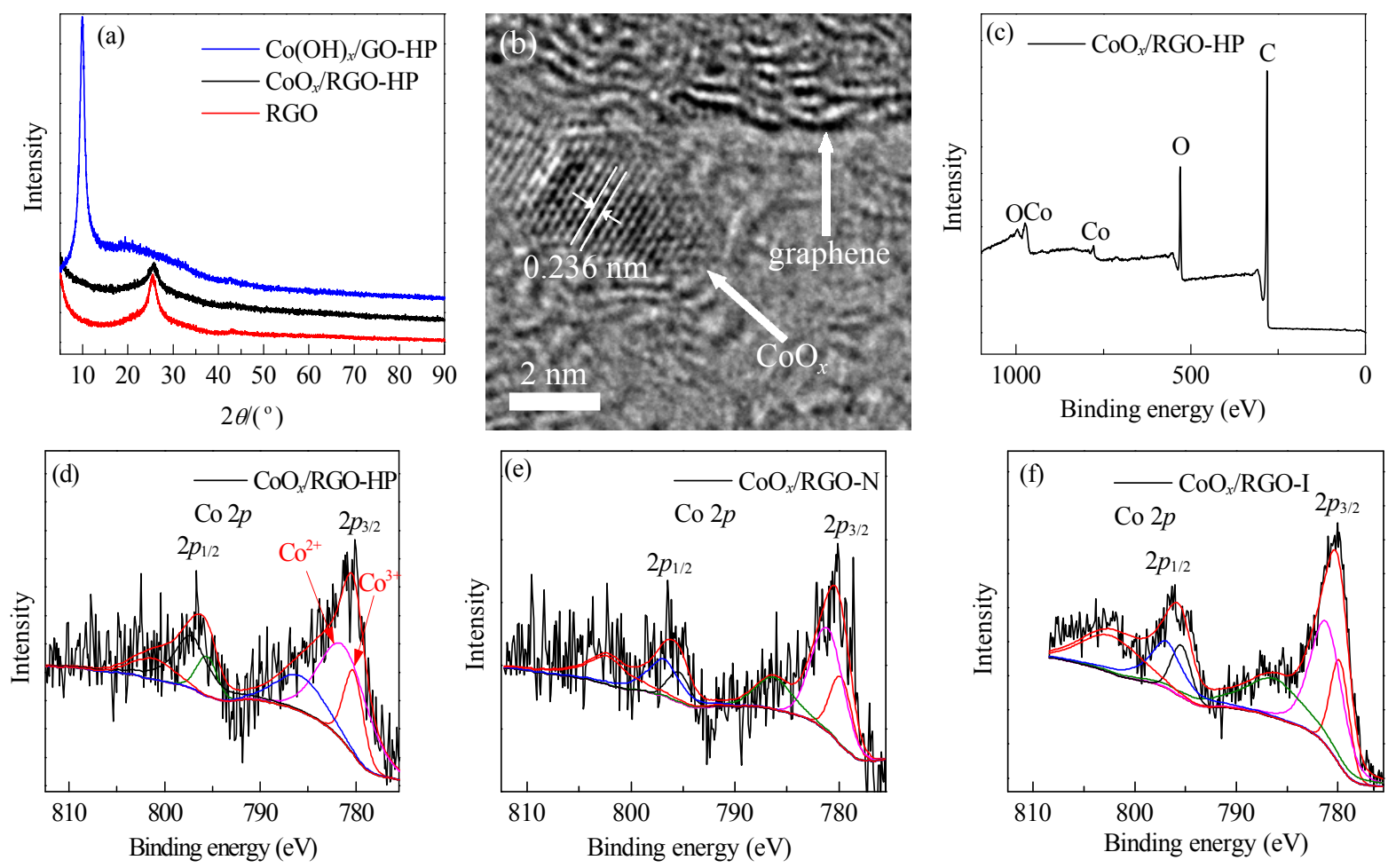

Fig. 4. (a) XRD patterns of RGO and its composites with Co species. (b) HRTEM image of $\mathrm{CoO}_{x} / \mathrm{RGO}-\mathrm{HP}$ catalyst. (c) Survey and (d) high-resolution XPS spectra of $\mathrm{CoO}_{x} / \mathrm{RGO}-\mathrm{HP}$. High-resolution Co $2 p$ spectra of (e) $\mathrm{CoO}_{x} / \mathrm{RGO}-\mathrm{N}$ and (f) $\mathrm{CoO}_{x} / \mathrm{RGO}-\mathrm{I}$.
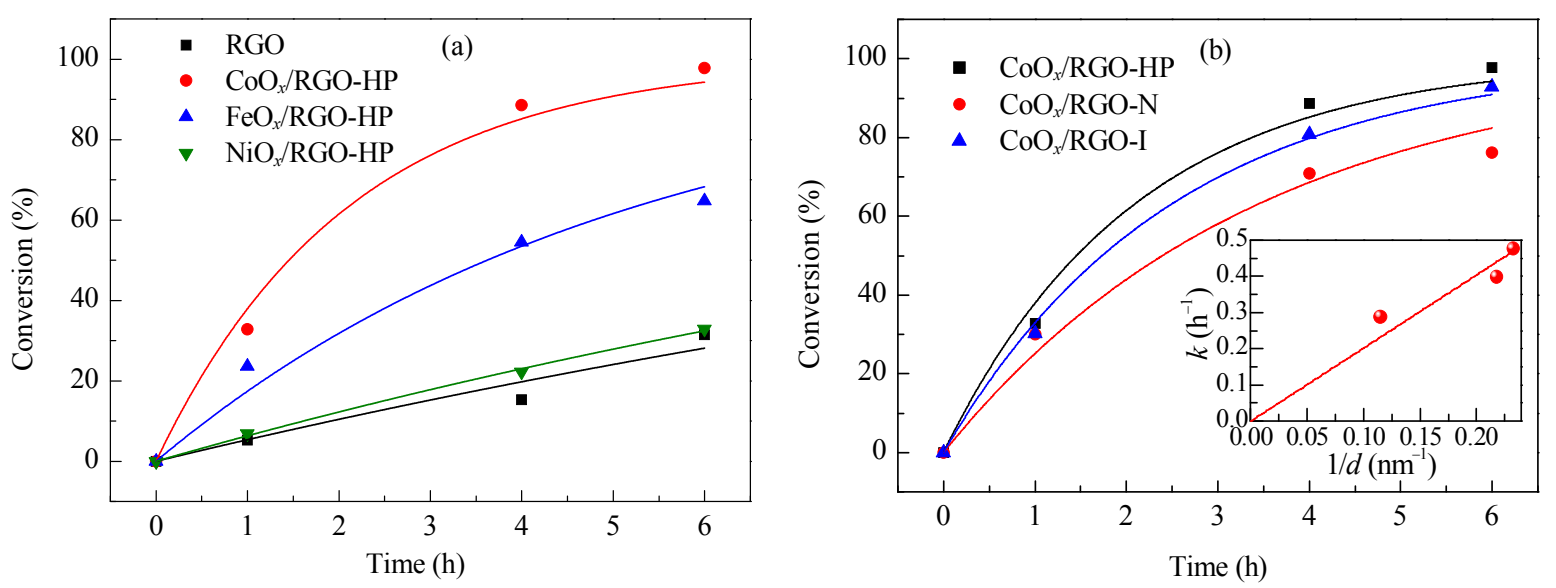

Fig. 5. (a) The conversion of benzyl alcohol on $\mathrm{RGO}, \mathrm{CoO}_{x} / \mathrm{RGO} \mathrm{FeO}_{x} / \mathrm{RGO}$, and $\mathrm{NiO}_{x} / \mathrm{RGO}$ catalysts prepared by the HOP method. (b) Effect of preparation method on the conversion of benzyl alcohol on $\mathrm{CoO}_{x} / \mathrm{RGO}$ catalysts. The curves in (a) and (b) are fitted with pseudo-first-order kinetics. Reaction conditions: $100 \mathrm{mg}$ alcohol, $5 \mathrm{~mL}$ of acetonitrile as solvent, $0.4 \mathrm{~mL}$ TBHP $(70 \%), 10 \mathrm{mg}$ catalyst, $110^{\circ} \mathrm{C}, 1-6 \mathrm{~h}$. 
catalytic reactions, such as $\mathrm{CO}$ oxidation [52], cathodic oxygen reduction reactions for fuel cells [53] and $\mathrm{Li}-\mathrm{O}_{2}$ batteries [54], water-splitting [55], and benzene hydrogenation [56].

\section{Conclusions}

In summary, the particle sizes and distributions of RGO supported metal oxides can be controlled by maintaining the oxygen-containing groups of GO or adjusting the nucleation speed. The deposition method assisted by $\mathrm{H}_{2} \mathrm{O}_{2}$ was optimal for growing highly dispersed iron, cobalt and nickel oxide NPs with mean diameters of $3.6,4.3$, and $5.8 \mathrm{~nm}$, respectively. The catalytic relevance of the particle size was demonstrated in the oxidation of benzyl alcohol, showing the crucial role of effective methods for size-controlled nanocatalysts on GO.

\section{References}

[1] Balaya P. Energy Environ Sci, 2008, 1: 645

[2] Cheng M Y, Ye Y S, Chiu T M, Pan C J, Hwang B J. J Power Sources, 2014, 253: 27

[3] Li Y, Liu Q Y, Shen W J. Dalton Trans, 2011, 40: 5811

[4] Hu H, Zhao Z B, Wan W B, Gogotsi Y, Qiu J S. Adv Mater, 2013, 25 : 2219

[5] Wang Z L, Xu D, Wang H G, Wu Z, Zhang X B. ACS Nano, 2013, 7: 2422

[6] Phua P H, Lefort L, Boogers J A F, de Tristany M, Vries J G. Chem Commun, 2009: 3747

[7] Lin J K, Qiao B T, Liu J Y, Huang Y Q, Wang A Q, Li L, Zhang W S, Allard L F, Wang X D, Zhang T. Angew Chem Int Ed, 2012, 51: 2920

[8] Zhu J, Kailasam K, Fischer A, Thomas A. ACS Catal, 2011, 1: 342

[9] He Q G, Li Q Khene S, Ren X M, López-Suárez F E, Lozano-Castelló D, Bueno-López A, Wu G. J Phys Chem C, 2013, 117: 8697

[10] Galvis H M T, Bitter J H, Davidian T, Ruitenbeek M, Dugulan A I, de Jong K P. J Am Chem Soc, 2012, 134: 16207

[11] Fu T J, Lü J, Li Z H. Ind Eng Chem Res, 2014, 53: 1342

[12] Yang Y F, Jia L T, Hou B, Li D B, Wang J G, Sun Y H. Catal Lett, 2014, 144: 133

[13] Pina G, Louis C, Keane M A. Phys Chem Chem Phys, 2003, 5: 1924

[14] Du A J, Ng Y H, Bell N J, Zhu Z H, Amal R, Smith S C. J Phys Chem Lett, 2011, 2: 894

[15] Sun Y Q, Shi G Q.J Polym Sci Pt B-Polym Phys, 2013, 51: 231

[16] Kou R, Shao Y Y, Wang D H, Engelhard M H, Kwak J H, Wang J,
Viswanathan V V, Wang C M, Lin Y H, Wang Y, Aksay I A, Liu J. Electrochem Commun, 2009, 11: 954

[17] Dong X C, Xu H, Wang X W, Huang Y X, Chan-Park M B, Zhang H, Wang L H, Huang W, Chen P. ACS Nano, 2012, 6: 3206

[18] Gao Y J, Ma D, Hu G, Zhai P, Bao X H, Zhu B, Zhang B S, Su D S. Angew Chem Int Ed, 2011, 50: 10236

[19] Byon H R, Suntivich J, Shao-Horn Y. Chem Mater, 2011, 23: 3421

[20] Zhang G Q, Lou X W. Sci Rep, 2013, 3: 1470

[21] Myung S, Park J, Lee H, Kim K S, Hong S. Adv Mater, 2010, 22 : 2045

[22] Mao S, Lu G H, Yu K H, Bo Z. Chen J H. Adv Mater, 2010, 22: 3521

[23] Zhang G Q, Xia B Y, Wang X, Lou X W. Adv Mater, 2013, 26: 2408

[24] Tien H W, Huang Y L, Yang S Y, Wang J Y, Ma C M. Carbon, 2011, 49: 1550

[25] Ha H W, Choudhury A, Kamal T, Kim D H, Park S Y. ACS Appl Mater Inter, 2012, 4: 4623

[26] Ji Z Y, Shen X P, Zhu G X, Zhou H, Yuan A H.J Mater Chem, 2012, 22: 3471

[27] Wu Z S, Ren W C, Wen L, Gao L B, Zhao J P, Chen Z P, Zhou G M, Li F, Cheng H M. ACS Nano, 2010, 4: 3187

[28] Gotoh K, Kinumoto T, Fujii E, Yamamoto A, Hashimoto H, Ohkubo T, Itadani A, Kuroda Y, Ishida H. Carbon, 2011, 49: 1118

[29] Liu Y W, Guan M X, Feng L, Deng S L, Bao J F, Xie S Y, Chen Z, Huang R B, Zheng L S. Nanotechnol, 2013, 24: 025604

[30] Ren L L, Huang S, Fan W, Liu T X. Appl Surf Sci, 2011, 258: 1132

[31] Zhu J X, Sharma Y K, Zeng Z Y, Zhang X J, Srinivasan M, Mhaisalkar S, Zhang H, Hng H H, Yan Q Y.J Phys Chem C, 2011, 115: 8400

[32] Fang M, Chen Z X, Wang S Z, Lu H B. Nanotechnol, 2012, 23: 085704

[33] Fu X B, Yu H, Peng F, Wang H J, Qian Y. Appl Catal A, 2007, 321: 190

[34] Wu Y S, Yu H, Peng F, Wang H J. Mater Lett, 2012, 67: 245

[35] Chen Y T, Wang H P, Liu C J, Zeng Z Y, Zhang H, Zhou C M, Jia X L, Yang Y H.J Catal, 2012, 289: 105

[36] Chen H, Tang Q H, Chen Y T, Yan Y B, Zhou C M, Guo Z, Jia X L, Yang Y H. Catal Sci Technol, 2013, 3: 328

[37] Zhou C M, Chen H, Yan Y B, Jia X L, Liu C J, Yang Y H. Catal Today, 2013, 211: 104

[38] Zhou X T, Ji H B. Chin J Catal (周贤太, 纪红兵. 催化学报), 2012, 33: 1906

[39] Wu S X, He Q Y, Zhou C M, Qi X Y, Huang X, Yin Z Y, Yang Y H, Zhang H. Nanoscale, 2012, 4: 2478

[40] Ali S R, Chandra P, Latwal M, Jain S K, Bansal V K, Singh S P. Chin J Catal (催化学报), 2011, 32: 1844

\section{Graphical Abstract}

Chin. J. Catal., 2014, 35: 952-959 doi: 10.1016/S1872-2067(14)60114-5

\section{Controllable synthesis and catalytic performance of graphene-supported metal oxide nanoparticles}

Yingsi Wu, Hao Yu*, Hongjuan Wang, Feng Peng* South China University of Technology

Three methods have been applied to synthesize graphene-supported metal oxide nanoparticles, among which the $\mathrm{H}_{2} \mathrm{O}_{2}$ homogeneous oxidation precipitation method leads to the highest dispersion and the most uniform size distribution.

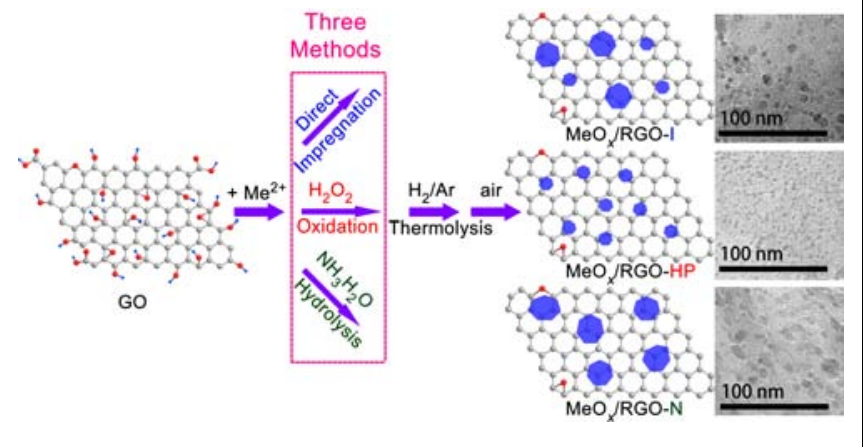


[41] Kovtyukhova N I, Ollivier P J, Martin B R, Mallouk T E, Chizhik S A, Buzaneva E V, Gorchinskiy A D. Chem Mater, 1999, 11: 771

[42] Zhang J T, Xiong Z G, Zhao X S. J Mater Chem, 2011, 21: 3634

[43] Tuxen A, Carenco S, Chintapalli M, Chuang C H, Escudero C, Pach E, Jiang B, Borondics F, Beberwyck B, Alivisatos A P, Thornton G, Pong W F, Guo J H, Perez R, Besenbacher F, Salmeron M. J Am Chem Soc, 2013, 135: 2273

[44] Wang C M, Baer D R, Amonette J E, Engelhard M H, Antony J, Qiang Y. J Am Chem Soc, 2009, 131: 8824

[45] Koo B, Xiong H, Slater M D, Prakapenka V B, Baasubramanian M, Podsiadlo P, Johnson C S, Rajh T, Shevchenko E V. Nano Lett, 2012, 12: 2429

[46] Yan J, Zhao Z W, Pan L K. Phys Status Solidi (A), 2011, 208: 2335

[47] Zhang Y J, Hu W B, Li B, Peng C, Fan C H, Huang Q. Nanotechnol, 2011, 22: 345601

[48] Li Y J, Li Y J, Zhu E B, McLouth T, Chiu C Y, Huang X Q, Huang Y. J Am Chem Soc, 2012, 134: 12326

[49] Chuang T J, Brundle C R, Rice D W. Surf Sci, 1976, 59: 413
[50] Ji H B, Wang T T, Zhang M Y, Chen Q L, Gao X N. React Kinet Catal Lett, 2007, 90: 251

[51] Tuxen A, Carenco S, Chintapalli M, Chuang C H, Escudero C, Pach E, Jiang P, Borondics F, Beberwyck B, Alivisatos A P, Thornton G, Pong W F, Guo J H, Perez R, Besenbacher F, Salmeron M. J Am Chem Soc, 2013, 135: 2273

[52] Yu Y B, Zhao J J, Han X, Zhang Y, Qin X B, Wang B Y. Chin J Catal (余 运波, 赵娇娇, 韩雪, 张燕, 秦秀波, 王宝义. 催化学报), 2013, 34: 283

[53] Yan X H, Zhang G R, Xu B Q. Chin J Catal (严祥辉, 张贵荣, 徐柏庆. 催化学报), 2013, 34: 1992

[54] Zhang K J, Zhang L X, Chen X, He X, Wang X G, Dong S M, Han P X, Zhang C J, Wang S, Gu L, Cui G L.J Phys Chem C, 2012, 117: 858

[55] Liao L, Zhang Q H, Su ZH, Zhao Z Z, Wang Y N, Li Y, Lu X X, Wei D G, Feng G Y, Yu Q K, Cai X J, Zhao J M, Ren Z F, Fang H, Robles-Hernandez F, Baldelli S, Bao J M. Nat Nanotechnol, 2014, 9: 69

[56] Zhu L H, Zheng L, Du K Q, Fu H, Li Y H, You G R, Chen B H. RSC Adv, 2013, 3: 713

\title{
石墨烯负载的金属氧化物纳米颗粒的可控制备及催化性能
}

\author{
伍颖斯, 余 皓 ${ }^{*}$, 王红娟, 彭 峰 ${ }^{\#}$ \\ 华南理工大学化学与化工学院, 广东广州510640
}

摘要: 采用直接浸渍法、过氧化氢均相氧化沉积法和氨水催化水解法制备了石墨烯负载的铁、钴、镍金属氧化物纳米颗粒. 研究 了三种沉积方法对颗粒尺寸分布的影响; 采用透射电子显微镜、傅里叶变换红外光谱、X射线衍射和X射线光电子能谱表征了催 化剂的形貌与结构. 用过氧化氢均相氧化沉淀法可制得粒径分布最均匀的纳米颗粒. 过氧化氢的氧化作用可使石墨烯表面的氧 化基团含量最大化, 为纳米颗粒提供了足够的吸附与成核点. 氨水加速了金属离子的水解与成核, 导致纳米颗粒的粒径增大与不 均. 以苯甲醇氧化为探针反应考察了催化剂的性能. 催化剂的活性按以下顺序逐渐下降: 过氧化氢辅助沉积法 > 直接浸渍法 > 氨水催化水解法, 与纳米颗粒尺寸增长趋势一致. 纳米催化剂颗粒尺寸与其活性的良好关联性显示, 发展石墨烯负载尺寸可控的 纳米催化剂的方法具有重要意义.

关键词: 颗粒尺寸; 石墨烯; 金属氧化物; 过氧化氢; 苯甲醇氧化

收稿日期: 2014-03-18. 接受日期: 2014-04-18. 出版日期: 2014-06-20.

*通讯联系人. 电话/传真: (020)87114916; 电子信箱: yuhao@scut.edu.cn

\#通讯联系人. 电话/传真: (020)87114916; 电子信箱: cefpeng@scut.edu.cn

基金来源：国家自然科学基金(20806027，21273079); 广东省自然科学基金(S20120011275); 新世纪优秀人才支持计划 (NCET-12-0190).

本文的英文电子版由Elsevier出版社在ScienceDirect上出版(http://www.sciencedirect.com/science/journal/18722067). 